\title{
Revisiting the Effect of Income on Health in Europe: Evidence from the 8th Round of the European Social Survey
}

\author{
Michail Papazoglou ${ }^{1} \cdot$ loannis Galariotis ${ }^{2}$ (D)
}

Accepted: 13 September 2019 / Published online: 19 September 2019

(c) Springer Nature B.V. 2019

\begin{abstract}
This study provides new evidence about the effects of income on population health. To do so, our first research question controls for the absolute income hypothesis: Has the recent deterioration of individual income had as a result a lower health status in population across European countries? We assume, as the bulk of the associated studies have found, that the lower the income of an individual, the lower his/her health status. Our second research objective is to examine the validity of the relative income hypothesis. To shed light on this issue, we test two different questions: What is the relationship between an individual's health status and a country's wealth and how self-rated health is associated with the degree of income inequality in a society? We expect that the population in wealthier countries report higher health status and individuals who live in countries with higher income inequalities report lower health status. By employing a multilevel binomial model and treating data from the latest European Social Survey Round 8 (2016/2017) from 23 countries in Europe, we have found strong evidence in favor of the above-mentioned hypotheses.
\end{abstract}

Keywords Income inequality $\cdot$ Individual income $\cdot$ Self-rated health $\cdot$ Europe $\cdot$ Multilevel modeling $\cdot$ Binary logistic regression

\section{Introduction}

The effect of income on population health has been variously studied across countries (Adler et al. 1993; Babones 2008; Bakkeli 2016; Clarke et al. 2002). Evidence has shown that there is a positive association between the income of an individual and his/her health condition. This has been stated as the absolute income hypothesis in the wider literature that examines the relationship between health and income (Ecob and Davey Smith 1999; Holstein et al. 2009; Pickett and Wilkinson 2015; Wilkinson and Pickett 2006). Richard Wilkinson was among the

Ioannis Galariotis

Ioannis.Galariotis@eui.eu

Michail Papazoglou

papazogloumichail@gmail.com

1 Unisystems S.A., Via Michelangelo. Buonarroti 39, 20145 Milan, Italy

2 School of Transnational Governance, European University Institute, Via dei Roccettini, San Domenico di Fiesole, Italy 
first scholars who argued that one of the main determinants of population health is the degree of income inequality in developed economies rather than the amount of individual income per se (Wilkinson 1996, 1998). In the jargon of Wilkinson analysis, this refers to the relative income hypothesis and most of the related literature has indicated an inverse association between income inequality and health: the higher the income inequality in a country, the lower the health among its population.

Over the years, Wilkinson's argumentation has received diverse criticisms about the techniques of his methodology and its subsequent argumentation. The main body of criticism is based on the argument that he has provided empirical evidence that "inter-country variations in health are significantly linked to intra-country variations in income, but he did so by using data that had been aggregated to the country level" (Jen et al. 2009, 643). This aggregate methodology is potentially flawed because associations between population health and income inequality can be deduced at the country level "even if there is no underlying relation between the distribution of income and the risk of mortality at the level of the individual" (Gravelle 1998; Gravelle et al. 2002; Jen et al. 2009).

In order to shed fresh light on both the absolute and relative income hypotheses regarding the effect of income on population health, we employ two binary multilevel logistic models on data gathered from the 8th round of the European Social Survey (2016/2017). Our first research question controls for the absolute income hypothesis: Has the recent deterioration of individual income had as a result a lower health status in population across European countries? We assume, as the bulk of the associated studies have found, that the lower the income of an individual, the lower his/her health status (hypothesis \#1). Our second research objective is to examine the validity of the relative income hypothesis. To do so, we are interested in providing evidence for two different questions: What is the relationship between an individual's health status and a country's wealth and how self-rated health is associated with the degree of income inequality in a society? We expect that the population in wealthier countries report higher health status (hypothesis \#2) and individuals who live in countries with higher income inequalities report lower health status (hypothesis \#3).

This study contributes to the widely explored literature of the absolute and relative income hypotheses by evaluating the role of individual and contextual variables concerning the relationship between income and health. We use the latest available data from the European Social Survey (ESS) Round 8 in order to control for new developments about income and health in several European countries. While the results of this study confirm the absolute income hypothesis, i.e. the higher the income of an individual the higher the probability of reporting good health, the results about the relative income hypothesis can stimulate several discussions: for instance, why among countries below the average Eurozone's GDP an inverse association between income inequalities and health exists while the contrary is observed among countries above the average Eurozone's GDP?

In the next section, we elaborate on the methods, i.e. datasets, sample, study design and variables, we have employed to accomplish our study. Following that, we present our results and discuss our contribution along the lines of the linked existing literature. The concluding section summarizes our findings and suggests further research tasks. 


\section{Methods}

\subsection{Data and Study Sample}

We have used data from the 8th round of the European Social Survey (ESS) conducted in 2016/2017 and released on the 30th of May 2018 (this is the second edition of the ESS Round 8 data). The dataset is a compilation of information from the following countries: Austria, Belgium, Czech Republic, Estonia, Finland, France, Germany, Hungary, Iceland, Ireland, Israel, Italy, Lithuania, Netherlands, Norway, Poland, Portugal, Russian Federation, Slovenia, Spain, Sweden, Switzerland and United Kingdom. Our sample consists of 44,387 individuals who are resident within private households, nested within 23 countries, aged 15 and over. The ESS is a biennial survey across countries initiated in 2002 and its main purpose is to track and decipher any sort of changes in public attitudes within Europe regarding numerous institutions and policy areas (European Social Survey 2018). The minimum target response rate is approaching the $70 \%$, while robust translation protocols are used so as to ensure comparability across countries. ${ }^{1}$

In addition, we rely on two different datasets to gather data for our country level variables. The World Bank provides data for mean income across countries (World Bank 2018). We have used Gross Domestic Product (GDP) per capita in purchasing power parity (PPP) for 2016 (GDP pc PPP from now on). In this respect, we follow the strategy of Jen et al. (2009). GDP per capita is a measure of the final product of goods and services of an economy divided by its population, including the residents and foreigners within a particular territory (typically, a country) for a given period of time. PPP represents price differences across countries allowing comparisons internationally. Income inequality is measured by the Gini coefficient, a widely accepted measure for this purpose (Dorfman 1979). The Organization for Economic Cooperation and Development (OEDC) provides data for income inequality across countries (OECD 2018). We have used the 2015 Gini coefficients for Spain, Finland, United Kingdom, Israel, Lithuania, Netherlands and Portugal. For the other countries of our sample, we have used their 2014 Gini coefficients (there are the most recent available data for the GINI coefficients from the OECD databases; the differences because the 2014 and 2015 GINI coefficients are negligible).

\subsection{Response Variable: Self-rated Health}

Self-rated health status is operationalized using the following question in the ESS questionnaire: "How is your health in general?". The ESS respondents were asked to evaluate their health condition based on five possible answers: 'very good' (1), 'good' (2), 'fair' (3), 'bad' (4) and 'very bad' (5). We have recoded our response variable into three categories (very good/good health, fair health and very bad/bad health) and we have used 'very good/ good' as a base.

\footnotetext{
${ }^{1}$ Despite its careful construction as a comparative cross-national survey, the ESS suffers from non-sampling errors such as frame errors, measurement errors, response and non-response errors and interviewer errors (for a thorough discussion of non-sampling errors and remedies to mediate them see, for example, at Groves et al. 2004; Lessler and Kalsbeek 1992; McNabb 2013). This sort of errors has an impact on the results of our analysis. We provide a few arguments about how these errors affect the results of this study in the discussion section.
} 


\subsection{Explanatory and Control Variables}

Our main explanatory variable is individual income (we have used the item 'Total household's net income' in the ESS dataset). Income plays a central role in our analysis since the three hypotheses of this study are guided by income differences and inequality among countries. We have divided income into five categories to capture the variation among a big number of income groups within countries. Our categories are from the lowest to the highest income group as follows: $1 \& 2$ deciles, $3 \& 4,5 \& 6,7 \& 8$ and $9 \& 10$ deciles. The European Union Statistics on Income and Living Conditions (EU-SILC) is one of the main sources of the variable 'income' of the ESS (European Social Survey 2016-ESS8 Appendix A2 Income ed.2.1). ${ }^{2}$ The income distribution per country is divided, by the ESS, in deciles, which represent different income bounds for each country. For all countries, ten different income categories have been defined, from the lowest to the highest income category. These income bounds (i.e. categories) have been created by each country's principal investigators and, therefore, are different per country. For example, the 5th decile in Germany, which is a rich country, is not the same as the 5th decile in Lithuania, which is a less rich country. In this respect, it is obvious that the income variable presents 'uneven distributions of income scales across countries' (Donnelly and Pop-Eleches 2018). Coupled with that, many inconsistencies can be observed across countries concerning the questionnaire that is used for the household income (Donnelly and Pop-Eleches 2018). For instance, the definition of the household components may differ among the countries. As HoffmeyerZlotnik and Warner (2006) characteristically state, "In Germany, the household definition focuses on the common kitchen...In Italy, the household is defined by the common atrium...In Luxembourg, the shared living room identifies the household unit" (HoffmeyerZlotnik and Warner 2006, p. 56). Therefore, controlling for the number of household components can be a misleading approach given the different understandings of households across countries. In more general respects, we fully recognize the problematic nature of the variable 'income' in this sort of cross-national surveys, such as the ESS. In order to provide an analysis that is comparable to existing studies, we follow similar techniques from other studies concerning the treatment of the income variable (look, for example, Jen et al. 2009 who have followed a similar approach; Alesina and Giuliano 2009).

In addition, we have controlled for numerous sociodemographic characteristics that are available from the ESS dataset. From the existing literature, we have traced that the following variables may have an effect on population health: age (centered around the mean which is 49.14 years), gender, education, welfare state performance and ever been divorced or had civil union dissolved (Balaj et al. 2017; Jen et al. 2009; Kennedy et al. 1998).

The variable 'age' is calculated and centered around the mean so that more reliable estimators of coefficients can be ensured ((Bell et al. 2018). ${ }^{3}$ The relationship between 'selfrated health' and 'age' is non-linear, because when we include a transformation of 'age' in its square format in our models, the results of the variables 'age' and 'age square format' are statistically significant (look at Table 2). We have proceeded to this transformation of the variable 'age', i.e. age square format, in order to improve the estimates of the coefficients.

\footnotetext{
2 Available at: https://www.europeansocialsurvey.org/docs/round8/survey/ESS8_appendix_a2_e02_1.pdf, accessed 26/3/2019.

3 Look, also, at the European Social Survey suggestions when preparing data for multilevel models' analyses at: http://essedunet.nsd.uib.no/cms/topics/multilevel/ch5/2.html.
} 
The variable education has been divided into three categories, i.e. low, medium and high, based on ISCED 2011 (International Standard Classification of Education 2011) (Eurostat 2016). ISCED 2011 has nine education levels and has been employed for all EU data collections since 2014 (the ESS8 is using this methodology). The 'low' category contains: ISCED 0, ISCED 1 and ISCED 2. The 'medium' category contains: ISCED 3, ISCED 4 and ISCED 5. The 'high' category contains: ISCED 6, ISCED 7 and ISCED 8. ${ }^{4}$

The label of the variable 'welfare state performance' stems from the ESS4 (Svallfors 2012). It has been constructed based on the following items of the ESS8 questionnaire: item 'gvslvol—Standard of living for the old, governments' responsibility'; item 'gvslvueStandard of living for the unemployed, governments' responsibility'; and, item 'gvcldcrChild care services for working parents, governments' responsibility'. ${ }^{5}$ We have employed a Multiple Correspondence Analysis (MCA) technique to create this variable. MCA is an extension of the simple correspondence analysis when there are more than two categorical variables. It can be also deemed as a generalization of the principal component analysis when the variables are categorical instead of numeric (Abdi and Williams 2010). The Cronbach's alpha value is equal to 0.68 and, therefore, is acceptable for the implementation of the MCA. Finally, we have rescaled the values using a $0-10$ scale so as to improve the coefficients' interpretation.

\subsection{Country Level Variables}

Except for GDP pc PPP and Gini coefficient, we have created a measure entitled 'Eurozone's threshold', by centering each country's mean income measures in GDP pc PPP on the Eurozone's mean income. Employing this threshold, we can assess whether there are differences in self-rated health between countries above and below this sort of threshold.

In Table 1, we present the outcome, explanatory and control variables of this study, as well as country level variables, and outline some descriptive statistics about them.

\subsection{Statistical Modeling}

We build two multilevel binomial models: 'good/very good' compared to 'bad/very bad' and 'good/very good' compared to 'fair'. Taking into account the clustering of individuals' responses nested within countries, we have a structure of a two-level binomial logistic regression model. The binomial logistic regressions have been implemented using the statistical programming language $\mathrm{R}$ (version 3.4.3.) with maximum likelihood estimation procedure. In addition, we use the Akaike Information Criterion (AIC) for model comparison.

We handle missing data with listwise deletion (Bartlett et al. 2015). For both binary multilevel models, we have built a series of models in order to test our hypothesis. Model 1 is the null model, in which there are no predictor variables in its fixed part, while the intercept is allowed to vary between countries in the random part. The purpose of the null model is to estimate the total pattern of self-rated health but also to assess the between-country

\footnotetext{
${ }^{4}$ Look at: https://ec.europa.eu/eurostat/statistics-explained/index.php?title=International_\%20Standard _\%20Classification\%20_of_Education_(ISCED)\#Correspondence_between_ISCED_2011_and_ISCED $-1997$.

${ }^{5}$ For the theoretical underpinnings of this variable construction, look at the European Social Survey 2016 round 8 Welfare Final Module Template: https://www.europeansocialsurvey.org/docs/round8/questionnaire/ ESS8_welfare_final_module_template.pdf.
} 


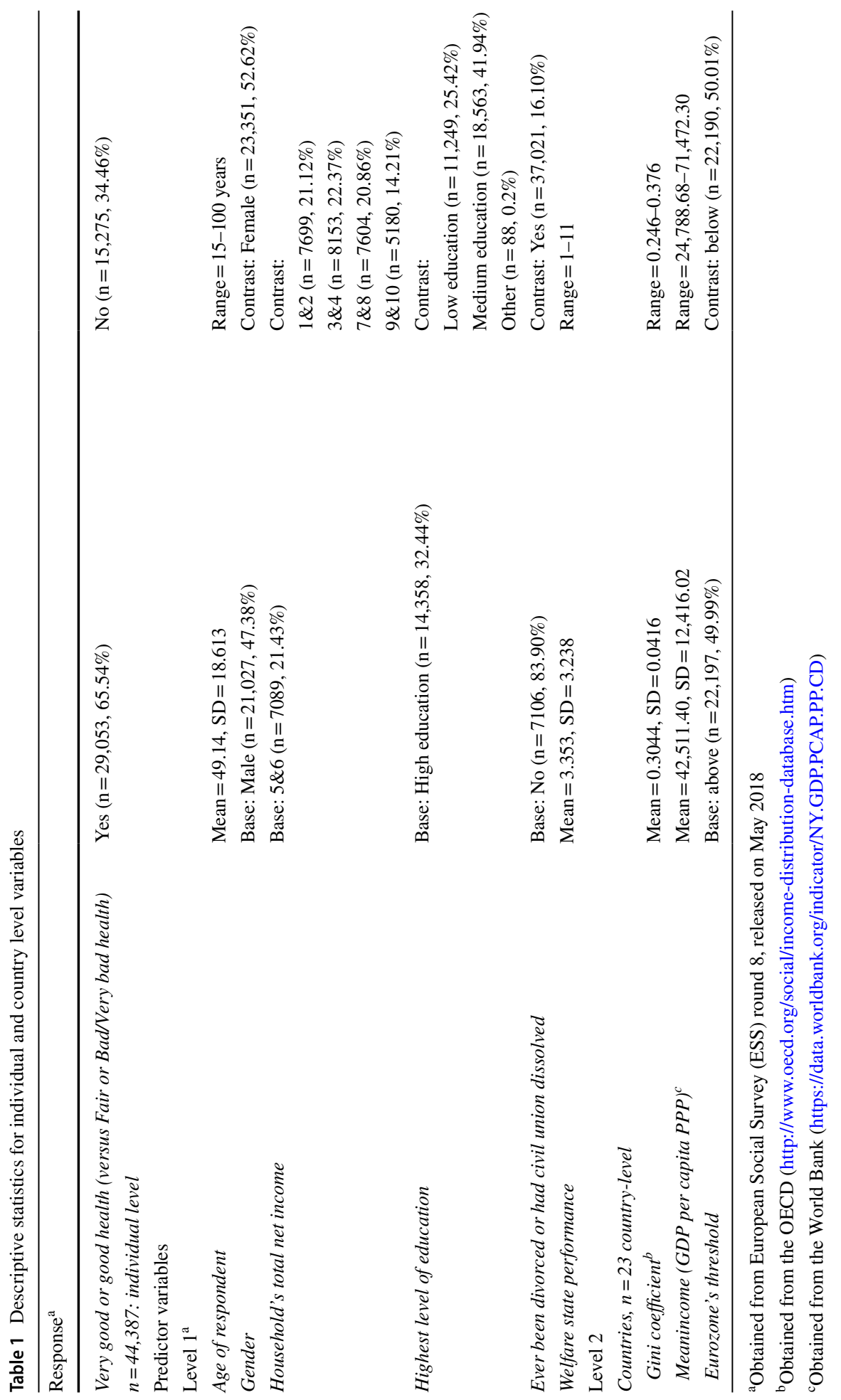


variation. Model 2 is an extension of the null model including all the individual predictors in the fixed part. It provides estimations regarding the effect of individuals' income and countries' classification on the self-rated level of health, controlling for all other individual characteristics. In the random part, the individual income variable varies at the country level and we estimate its effect for the different income groups: $1 \& 2$ and $3 \& 4$ deciles have combined into a new group (low income) and $7 \& 8$ and $9 \& 10$ deciles have combined into another one (high income). Level $5 \& 6$ has used as the reference group called middle income. This model estimates the variation in health between countries that remains inexplicable after considering the individual variables.

At model 3, we have added our two country level variables: the Gini coefficient and the GDP pc PPP. Model 4 expands model 3 by adding a cross-level interaction term between income inequalities, as measured by Gini coefficient, and the individual groups of household's total net income. This term shows us whether there is a relationship between income inequalities across Europe and individual health and, at the same time, whether there is variation of income inequalities on the self-rated health of people among different income groups (Subramanian and Kawachi 2006). Model 5 extends further model 4 by adding the fixed effect of a country's wealth on individual health. In addition, two more interactions have been inserted: the first one tests whether the mean income effect of each country differs for countries above and below Eurozone's mean income and the other one whether the income inequalities differ for countries above and below Eurozone's mean income. The average country income has been centered on the Eurozone's GDP $(42,059.77 \$)$, while the Gini coefficient has been centered around the mean.

\section{Results}

In Table 2, we present the results of our models. Apart from the parameter coefficients (beta), it also provides their standard errors, the Intraclass Correlation Coefficient (ICC) and the AIC. By transforming the logits intercept estimates in Models 1a and 1b into odds, ${ }^{6}$ we have odds equal to 0.116 and 0.401 respectively. This means that the odds of someone reported himself/herself in bad/very bad health are 0.116 times the odds of someone reported himself/herself good or very good in health. In addition, the odds of someone reported himself/herself in fair health is 0.401 times the odds of someone reported himself/ herself good or very good in health.

Figure 1 shows the relation between individual income groups and self-rated health. It depicts a very strong relationship for both models: people belonging to higher income groups tend to report better health (i.e. the probability of reporting bad/very bad health compared to reporting good/very good health is decreasing; same for the probability of reporting fair compared to good/very good). ${ }^{7}$ Our hypothesis \#1 seems to be fully supported by our data analysis.

Figure 2 is providing evidence for our hypothesis \#2: the relationship between the wealth of a country and its population health has a positive association (i.e. the higher the wealth of a country the higher the self-rated health of the individuals who reside in this

\footnotetext{
6 The beta coefficients in Table 2 are equal to $\log \frac{(p)}{(1-p)}$. But, $\frac{(p)}{(1-p)}$ is the odds, therefore coefficient $=\log$ (odds). If we raise the coefficient in $e$, namely $e^{\text {coefficient }}=$ odds.

7 The graphs represent probabilities according to the 'Effect' R package's documentation (Fox 2003).
} 


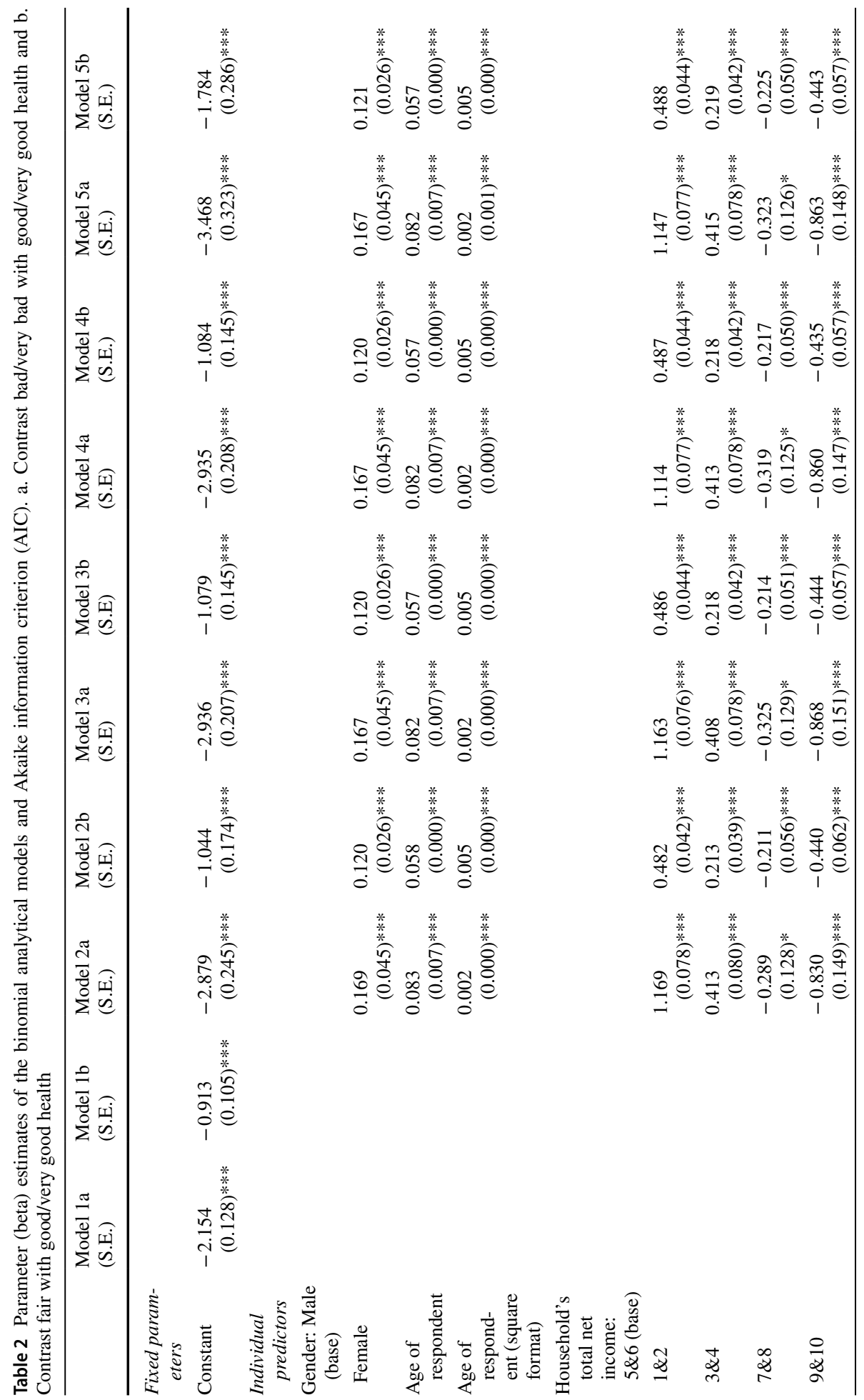




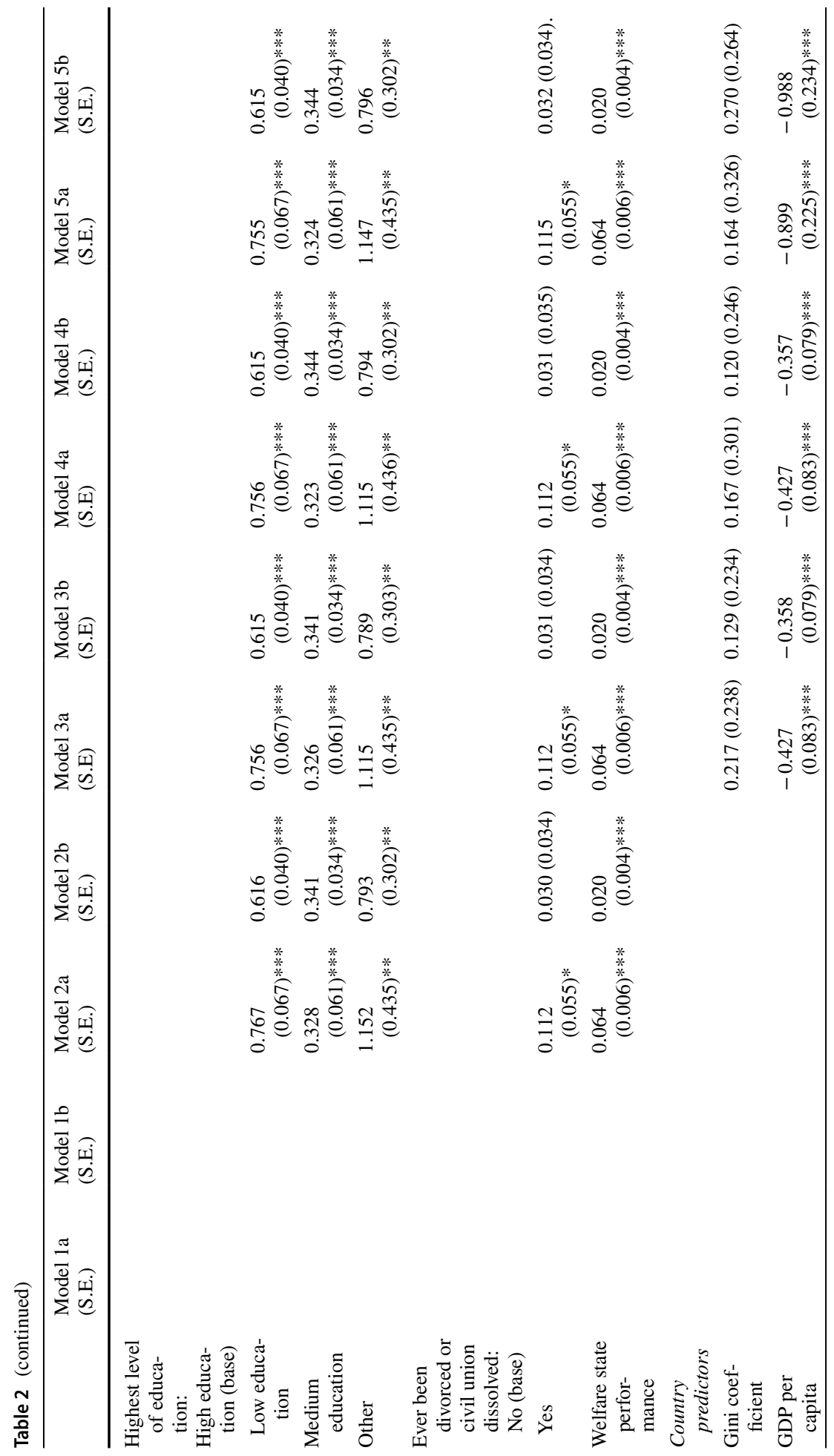




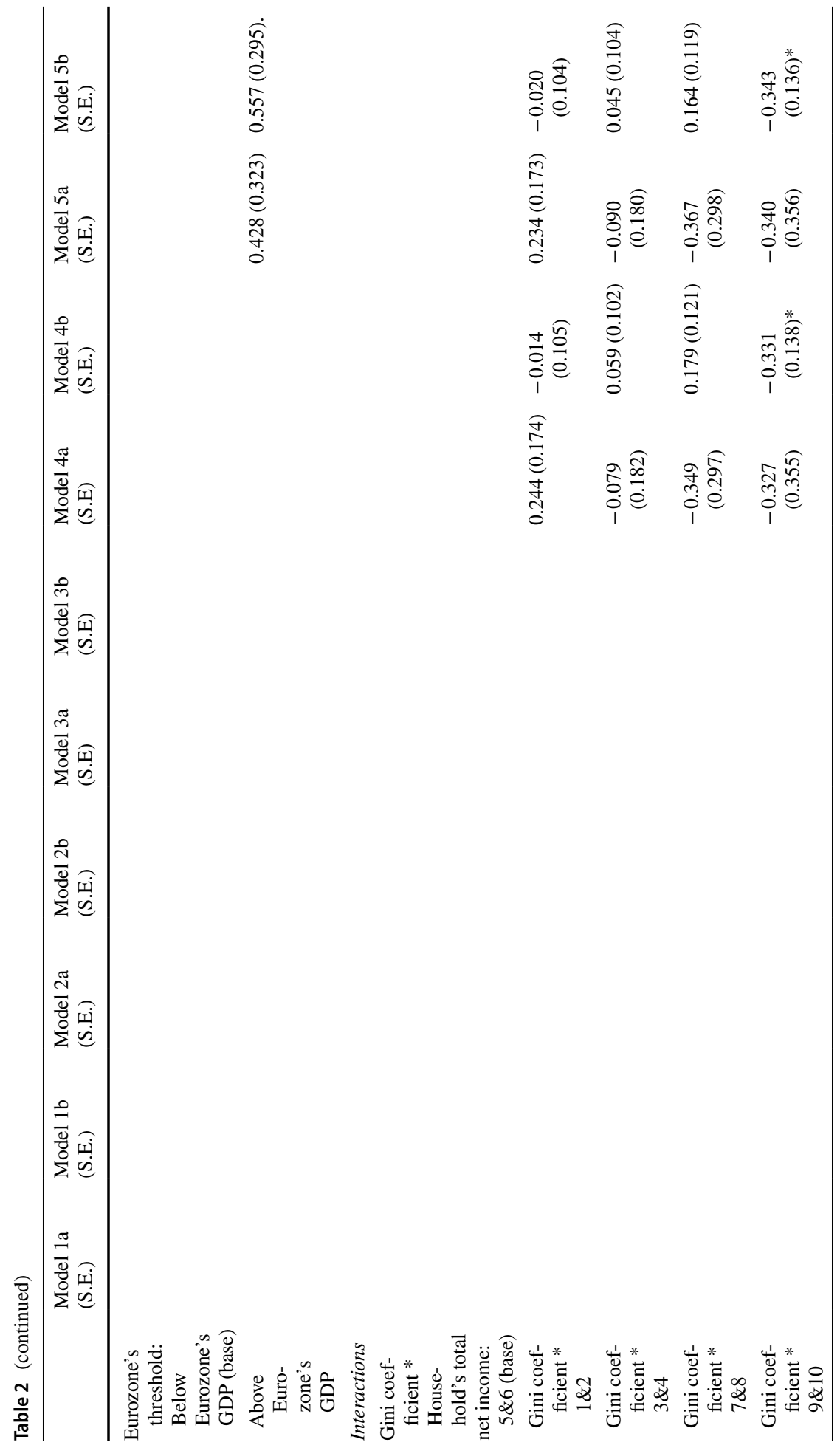




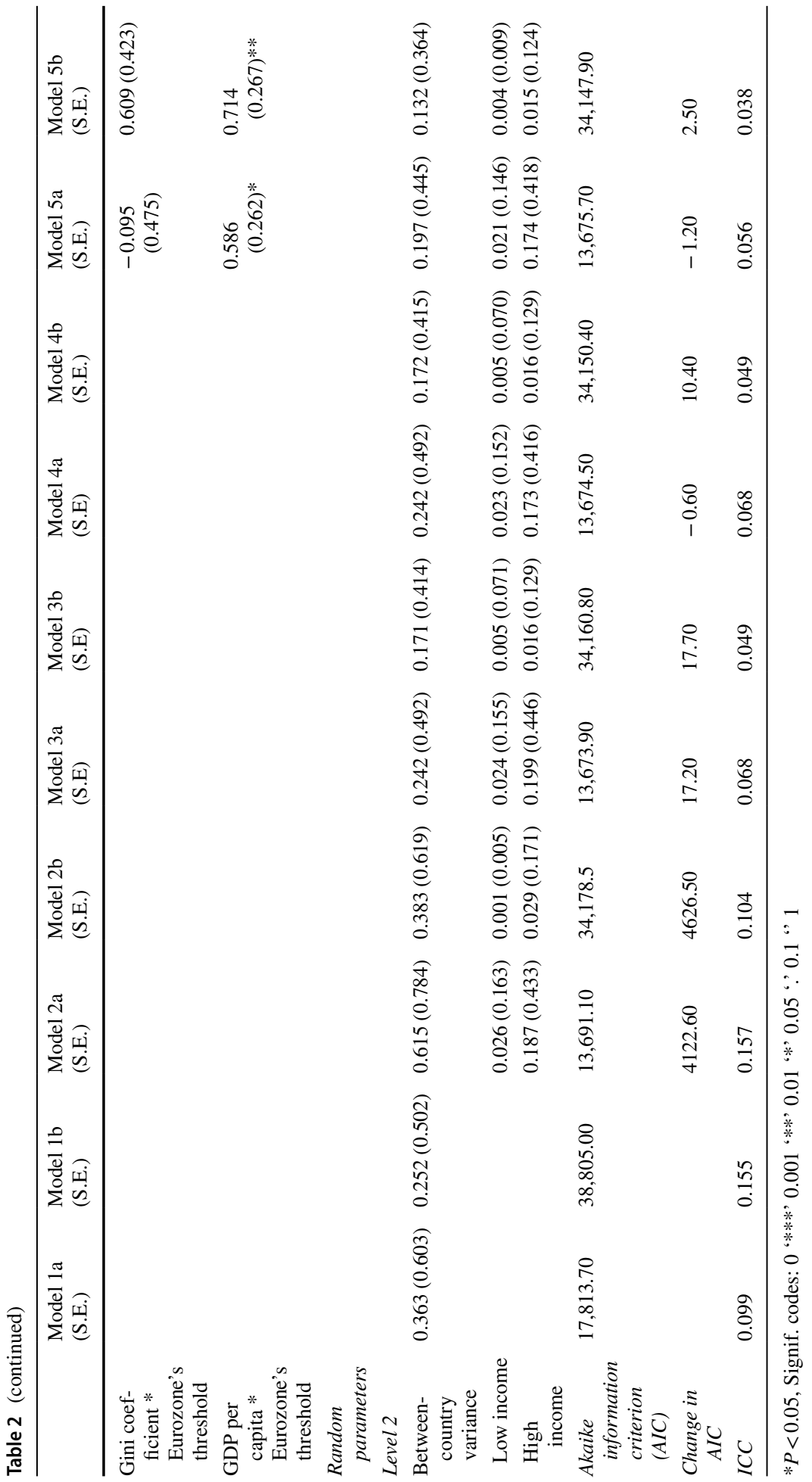



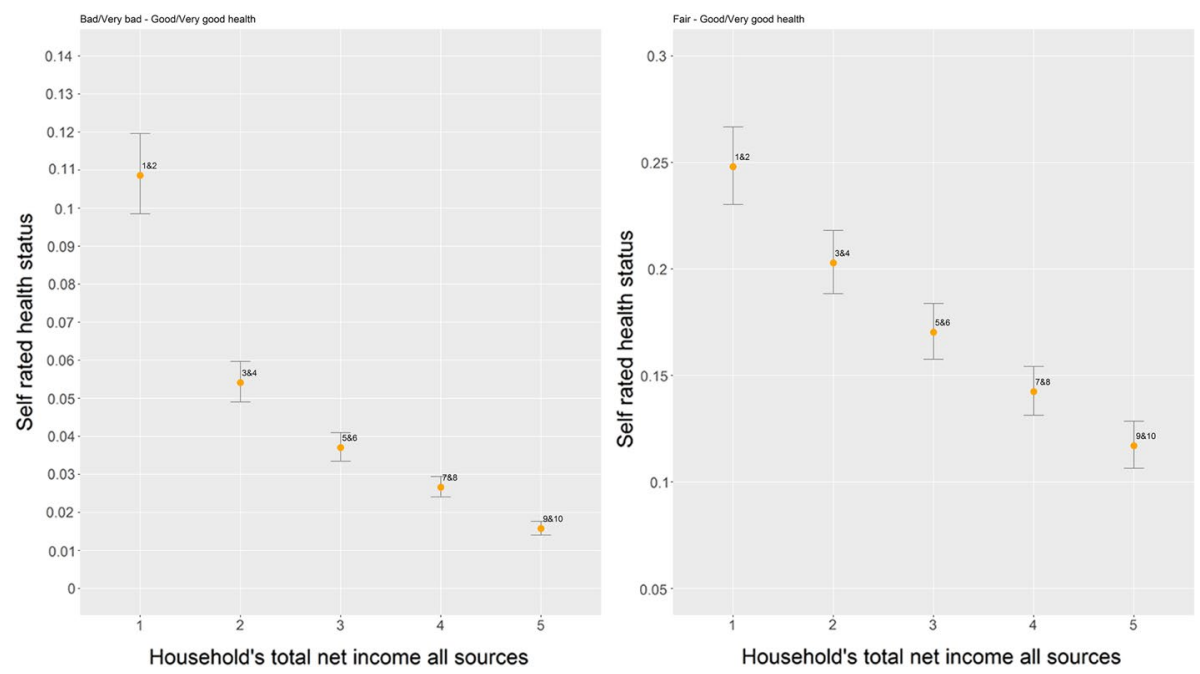

Fig. 1 Error bar between self-rated health and household's total net income
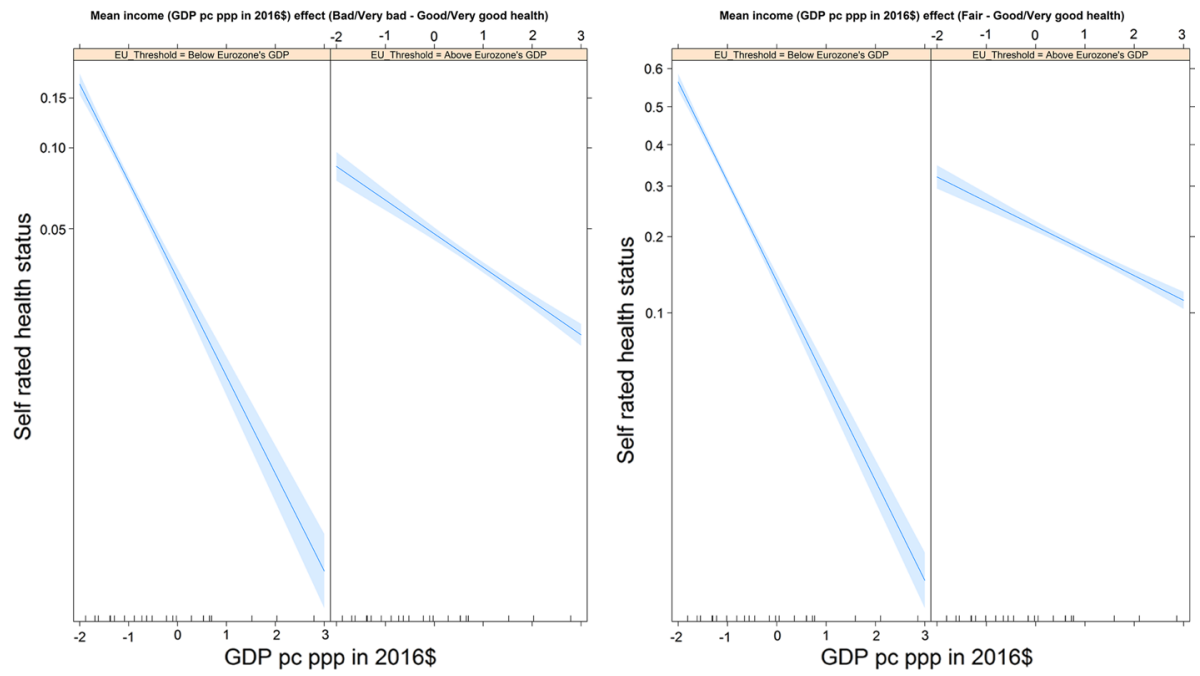

Fig. 2 Mean income effect for countries below and above Eurozone's threshold

country). We view that, in both groups of countries, the probabilities of reporting either bad/very bad health or fair health are decreasing as a country's wealth is increasing (Fox 2003). Our hypothesis is fully supported.

Our hypothesis \#3 suggests that individuals who live in countries with higher income inequality tend to report lower rates of health. Following Wilkinson's analysis, this is evident in developed countries and not in countries which have a high GDP level (he argues that the respective level is $10 \mathrm{k}$ per capita). In our sample, we do not study individuals who belong in developed countries, because all ESS countries, participating in this survey, are well above Wilkinson's threshold of $10 \mathrm{~K}$. 

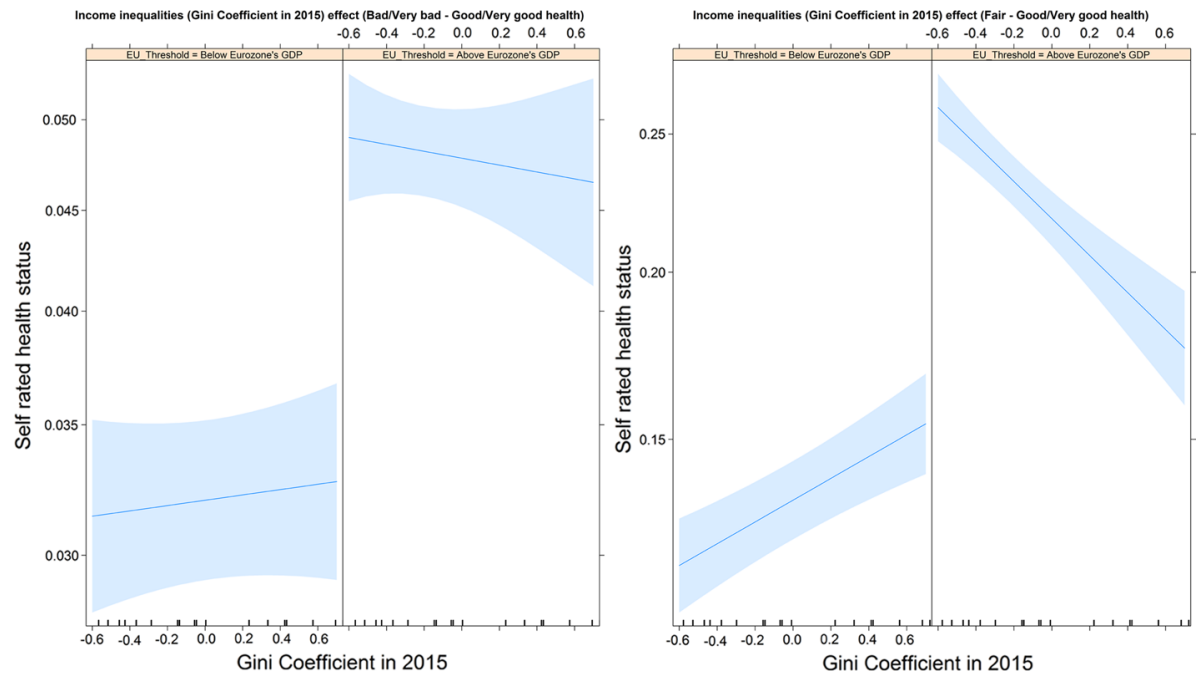

Fig. 3 Income inequality effect for countries below and above Eurozone's threshold

In this respect, we cannot provide comparable results to studies testing the Wilkinson hypothesis. However, we assume that individuals belonging in countries which are below the Eurozone's average GDP levels, most probably, will have the tendency to report lower health statuses compared to individuals who belong in countries which are above the Eurozone's average GDP levels. We proceed to this differentiation in order to trace any trends between income inequality and health in two different groups of countries: i.e. those below Eurozone's GDP average and those above Eurozone's GDP average.

Figure 3 shows the relationship between income inequality (as measured by the Gini coefficient level) and self-rated health status. For the group of countries below the average GDP level, we observe that the probabilities of reporting either bad/very bad or fair health compared to good/very good are increasing as the level of income inequality is increasing. This entails that individuals tend to report lower levels of self-rated health within countries with higher income inequalities in this group of countries. On the contrary, for the group of countries above the GDP average, we observe that the higher the level of income inequality the higher the status of self-rated health (the probabilities are decreasing). Our hypothesis seems to be partly proved: individuals in the group of countries with lower GDP as compared to the ones residing in the group of countries with higher GDP tend to report lower levels of health when income inequality is rising.

\section{Discussion}

The results of our analysis show a clear positive association between individuals' income and health status: the higher the income of an individual, the higher his/her health status (look at Fig. 1). Therefore, the absolute income hypothesis is confirmed by our sample analysis. The relative income hypothesis has been partly supported by the results of our study. We have investigated two hypotheses in the wider framework of the relative income literature: (a) the relation between the level of income of a country (i.e. the wealth of a 
country) and population health and (b) the level of income inequality in a country and population health.

For the former, we observe a positive association between the wealth of a country and population health: for both group of countries and for both our models, the higher the wealth of a country, the higher the self-rated health of population (look at Fig. 2). We further observe though that, in countries below the GDP average, wealth has a considerable impact on individual health conditions: the line is steeper compared to the one of the group of countries above the GDP average. This finding may suggest that an increase in the level of GDP may have a considerable positive effect on population health.

For the latter, for both our models, there is a mixed picture regarding the relationship between income inequality and population health. For the group of countries below the GDP average, the higher the income inequality, the lower the self-rated health of population; whereas, for the group of countries above the GDP average, the higher the income inequality, the higher the self-rated health of population (look at Fig. 3).

We recognize the limitations of our analysis. A cross-sectional study in a sample of 23 countries belonging to the wider geographical area of Europe, with quite similar characteristics concerning their sociodemographic structure cannot be considered as the ideal sample for the assessment of the effect of income level and income inequality on health population. Given this limitation, we have tried to mitigate the problematic nature of our sample by employing a multilevel modelling technique in order to examine contextuality at both the individual and country level and, coupled with that, to explore trends both within and between countries. Our small sample cannot be compared to studies with larger samples of countries that are going beyond the limited geographical region of Europe (see, for instance the analysis of Jen et al. 2009 for a global analysis with similar research objectives). However, our analysis is providing evidence for a small set of countries with quite similar sociodemographic characteristics. This entails that our findings have a robust interpretation given the homogeneity of our sample under investigation.

The most serious shortcoming of this analysis is the quality of the variable 'income' and how it is measured across countries. Several proposals have attempted to mediate this problem (look, for instance, Donnelly and Pop-Eleches 2018) so that researchers and analysts can obtain reliable measurements of income and make cross-national comparisons. The most frequent problem of the variable 'income' is the intensity of the missing responses about this variable in the ESS (and in similar cross-national surveys such as the World Values Survey and the International Social Survey Programme). Missing items (a type of a non-response error) reduce the available data and, therefore, the quality of the outcomes of numerous analyses (Molenberghs et al. 2004). Similarly, income questions increase the tendency of respondents to provide incorrect or social desirable answers (i.e. social desirability bias). Response errors, also, affect the quality of the results in cross-national surveys: for the case of 'income' variable, respondents frequently cannot report the correct values (respondent error) and/or interviewers either cannot report the accurate values (interviewer error). Likewise, instrument errors are quite strong in such surveys across countries: do the same instruments are used to measure the variable 'income' (measurement errors)? Finally, coverage errors are an important source of bias in cross-national surveys since there is a significant failure of coverage of all components of the population to be included in a study. This entails that major parts of the population are not providing information in the analyses (under-coverage) or, on the contrary, some portions of the society provide analogically more information compared to the total population (over-coverage).

Therefore, numerous sources of non-sampling errors based on income-related questions can affect the results of this analysis. While we are aware of the aforementioned problems, 
the ESS database still comprises a valuable source of data from which we can trace citizens behavior for numerous social phenomena, such as health status and its relation to income.

Despite the clear association of sociodemographic variables on health, this bunch of variables cannot alone explain differences or similarities across countries. Future endeavors should focus on additional variables, such as psychological factors, environmental trends, food and life habits related to health, access to healthcare services, to name but a few, that may have an effect on population health (Eikemo et al. 2008; Moore et al. 2006).

Acknowledgements We would like to thank Nevena Kulic (Max Weber Fellow at the European University Institute in Florence) and the two anonymous reviewers for providing useful comments and feedback.

\section{Compliance with Ethical Standards}

Conflict of interest The authors declare that they have no conflict of interest.

Human and Animal Rights This article does not contain any studies with human participants or animals performed by any of the authors.

\section{References}

Abdi, H., \& Williams, L. J. (2010). Principal component analysis. Wiley Interdisciplinary Reviews: Computational Statistics, 2(4), 433-459.

Adler, N., Boyce, T. W., Chesney, M. A., Folkman, S., \& Syme, S. L. (1993). Socioeconomic inequalities in health no easy solution. JAMA: The Journal of the American Medical Association, 269(24), 3140-3145.

Alesina, A., \& Giuliano, P. (2009). Preferences for redistribution. IZA discussion paper, (4056), Leibniz: Institute for the Study of Labor.

Babones, S. J. (2008). Income inequality and population health: Correlation and causality. Social Science and Medicine, 66(7), 1614-1626.

Bakkeli, N. Z. (2016). Income inequality and health in China: A panel data analysis. Social Science and Medicine, 157, 39-47.

Balaj, M., McNamara, C. L., Eikemo, T. A., \& Bambra, C. (2017). The social determinants of inequalities in self-reported health in Europe: Findings from the European social survey (2014) special module on the social determinants of health. European Journal of Public Health, 27(Supplement 1), 107-114.

Bartlett, J. W., Harel, O., \& Carpenter, J. R. (2015). Asymptotically unbiased estimation of exposure odds ratios in complete records logistic regression. American Journal of Epidemiology, 182(8), 730-736. https://doi.org/10.1093/aje/kwv114.

Bell, A., Jones, K., \& Fairbrother, M. (2018). Understanding and misunderstanding group mean centering: a commentary on Kelley et al.'s dangerous practice. Quality \& Quantity, 52(5), 2031-2036.

Clarke, P. M., Gerdtham, U. G., Johannesson, M., Bingefors, K., \& Smith, L. (2002). On the measurement of relative and absolute income-related health inequality. Social Science and Medicine, 55(11), 1923-1928.

Donnelly, M. J., \& Pop-Eleches, G. (2018). Income measures in cross-national surveys: Problems and solutions. Political Science Research and Methods, 6(2), 355-363.

Dorfman, R. (1979). A formula for the Gini coefficient. The Review of Economics and Statistics, 61(1), 146.

Ecob, R., \& Davey Smith, G. (1999). Income and health: What is the nature of the relationship? Social Science and Medicine, 48(5), 693-705.

Eikemo, T. A., Bambra, C., Judge, K., \& Ringdal, K. (2008). Welfare state regimes and differences in selfperceived health in Europe: A multilevel analysis. Social Science and Medicine, 66(11), 2281-2295.

European Social Survey. (2016). Welfare attitudes: Question design final module in template. London: ESS ERIC Headquarters c/o City University London. https://www.europeansocialsurvey.org/docs/round8/ questionnaire/ESS8_welfare_final_module_template.pdf. Retrieved May 26, 2019.

European Social Survey. (2018). Preparing the data. http://essedunet.nsd.uib.no/cms/topics/multilevel/ ch5/2.html. Retrieved May 19, 2019. 
Eurostat. (2016). International Standard Classification of Education (ISCED): Statistics explained. https:// ec.europa.eu/eurostat/statistics-explained/index.php?title=International_Standard_Classification_of_ Education_(ISCED)\#Correspondence_between_ISCED_2011_and_ISCED_1997. Retrieved May 26, 2019.

Fox, J. (2003). Effect displays for generalized linear models. Journal of Statistical Software, 8(15), 1-27.

Gravelle, H. (1998). How much of the relation between population mortality and unequal distribution of income is a statistical artefact? BMJ, 316(7128), 382.

Gravelle, H., Wildman, J., \& Sutton, M. (2002). Income, income inequality and health: What can we learn from aggregate data? Social Science and Medicine, 54(4), 577-589. https://doi.org/10.1016/S0277 -9536(01)00053-3.

Groves, R. M., Fowler, F. J., Couper, M. P., Lepkowski, J. M., Singer, E., \& Tourangeau, R. (2004). Survey methodology: Wiley series in survey methodology. New York, USA.

Hoffmeyer-Zlotnik, J., \& Warner, U. (2006). Methodological discussion of the income measure in the European social survey round 1. Metodološki zvezki, 3(2), 289-334.

Holstein, B. E., Currie, C., Boyce, W., Damsgaard, M. T., Gobina, I., Kökönyei, G., et al. (2009). Socioeconomic inequality in multiple health complaints among adolescents: International comparative study in 37 countries. International Journal of Public Health, 54(SUPPL. 2), 260-270.

Jen, M. H., Jones, K., \& Johnston, R. (2009). Global variations in health: Evaluating Wilkinson's income inequality hypothesis using the World Values Survey. Social Science and Medicine, 68(4), 643-653.

Kennedy, B. P., Kawachi, I., Glass, R., \& Prothrow-stith, D. (1998). Income distribution, socioeconomic status, and self rated health in the United States: Multilevel analysis. BMJ, 317(October), 917-921.

Lessler, J. T., \& Kalsbeek, W. D. (1992). Nonsampling error in surveys. Wiley series in probability and statistics. Hoboken: Wiley.

McNabb, D. E. (2013). Nonsampling error in social surveys. Thousand Oaks: Sage publications.

Molenberghs, G., Fitzmaurice, G., Kenward, M., Tsiatis, A., \& Verbeke, G. (Eds.). (2004). Handbook of missing data methodology. New York: CRC Press.

Moore, S., Teixeira, A. C., \& Shiell, A. (2006). The health of nations in a global context: Trade, global stratification, and infant mortality rates. Social Science and Medicine, 63(1), 165-178.

OECD. (2018). Income distribution database (IDD): Gini, poverty, income, methods and concepts. http:// www.oecd.org/social/income-distribution-database.htm. Retrieved July 30, 2018.

Pickett, K. E., \& Wilkinson, R. G. (2015). Income inequality and health: A causal review. Social Science and Medicine, 128, 316-326.

Subramanian, S. V., \& Kawachi, I. (2006). Whose health is affected by income inequality? A multilevel interaction analysis of contemporaneous and lagged effects of state income inequality on individual self-rated health in the United States. Health and Place, 12(2), 141-156. https://doi.org/10.1016/j.healt hplace.2004.11.001.

Svallfors, S. (2012). Welfare attitudes in Europe: Top line results from round 4 of the European social survey. Bergen: European Social Survey.

Wilkinson, R. G. (1996). Unhealthy societies: The afflictions of inequality. New York: Routledge.

Wilkinson, R. G. (1998). Mortality and distribution of income. Low relative income affects mortality. The British Medical Journal (Clinical Research Ed.), 136(7144), 1611.

Wilkinson, R. G., \& Pickett, K. E. (2006). Income inequality and population health: A review and explanation of the evidence. Social Science and Medicine, 62(7), 1768-1784.

WorldBank. (2018). GDP per capita, PPP | data. https://data.worldbank.org/indicator/NY.GDP.PCAP. PP.KD. Retrieved July 30, 2018.

Publisher's Note Springer Nature remains neutral with regard to jurisdictional claims in published maps and institutional affiliations. 